\title{
Sellado antibiótico de catéter y prolongador peritoneal ante peritonitis recidivante con sospecha de colonización
}

\author{
José Francisco Martínez Martinez, Rosa Ortells Coresa, Laura Navarro Daudén, Carme Moreno Aliaga, \\ Anna Marti i Monros
}

Enfermeras/os. Servicio Nefrología.Consocio Hospital General Universitario de Valencia

\section{Introducción}

La peritonitis es una de las principales complicaciones de los pacientes con diálisis peritoneal (DP) y en muchos casos conlleva la retirada del catéter y la transferencia temporal y/o definitiva a Hemodiálisis.

Según las últimas guías de tratamiento de las peritonitis, alrededor del $18 \%$ de las infecciones asociadas a mortalidad en pacientes sometidos a DP son peritonitis. Aunque menos del $4 \%$ de las mismas tienen como resultado la muerte $\mathrm{e}^{(1-2)}$.

Por otra parte los episodios repetidos de peritonitis pueden llegar a comprometer la membrana peritoneal y constituyen uno de los motivos más comunes de fallo de la técnica de DP.

El tratamiento debe instaurarse lo más rápidamente posible y para ello es muy importante la detección precoz (aparición de líquido turbio en el líquido peritoneal), aunque no se haya presentado clínica o sintomatología alguna.

Dicho tratamiento debe incluir la cobertura antibiótica tanto de bacterias grampositivas con vancomicina 0 cefalosporinas y gramnegativas con cefalosporinas de tercera generación o aminoglucósidos ${ }^{(3)}$.

La administración de dichos antibióticos resulta más efectiva en forma intraperitoneal (IP) que en forma intravenosa (IV).

\begin{tabular}{|c|}
\hline Correspondencia: \\
Anna Marti i Monros \\
Servicio de Nefrologia \\
Consorcio Hospital General Universitario de Valencia \\
Avda.Tres Cruces 2 \\
46014, Valencia \\
E-mail: anna.marti.monros@gmail.com
\end{tabular}

La constante aparición de gérmenes multiresistentes, también afecta a este tipo de infecciones por lo cual se plantean nuevos retos en el tratamiento de la peritonitis. La daptomicina puede resultar una opción valida en el tratamiento de infecciones causadas por gérmenes gram-positivos resistentes a meticilina y con sensibilidad intermedia a la vancomicina.

Además, la daptomicina es un fármaco que se utiliza actualmente en el tratamiento de las bacteriemias asociadas con catéteres intravenosos ${ }^{(4)}$ por su eficacia en el control de crecimiento en biofilm; por esta razón puede ser útil en el tratamiento del biofilm del catéter peritoneal.

\section{Caso clínico}

Presentamos el caso de un paciente con cuatro episodios de peritonitis enlazados y causados por el mismo germen (Staphylococus Epidermidis), Aureus nasal tratado con Bactroban nasal ${ }^{\circledR}$ y posible contaminación por corynebacterias) probablemente por colonización del catéter.

Paciente de 28 años diagnosticado de insuficiencia renal crónica estadio 5 secundaria a nefropatía intersticial probablemente por uropatía obstructiva vs. megaureter.

Inicio de HD de forma urgente por hiperpotasemia grave y síndrome urémico en mayo de 2011 , utilizándose como acceso vascular un catéter tunelizado de doble luz insertado en vena yugular derecha el 09/06/2011.

Una vez pasada la fase aguda de la insuficiencia renal, el paciente es informado de las diferentes modalidades de tratamiento sustitutivo de la función renal (TSFR).

El paciente se decide por la diálisis peritoneal continua ambulatoria (DPCA) como modalidad de tratamiento 
sustitutivo, insertándose el día 19/07/2011 un catéter autoposicionante para DP en fosa ilíaca derecha complicado en un primer momento con hemorragia local en sabana pero que no produce anemización.

El paciente inicia DPCA en su domicilio el día 06/09/2011 con un esquema inicial de tratamiento de cuatro cambios diarios con bolsas de $1,5 \%$ de glucosa y calcio bajo, manteniendo el paciente una diuresis residual de $1600 \mathrm{ml}$. $/ 24 \mathrm{~h}$.

\section{Primer episodio de peritonitis:}

Un mes después de inicio de DPCA (05/10/2011) y en una revisión rutinaria el paciente refiere que una de las bolsas del día anterior le pareció turbia y que en ese momento tenia "pinchazos" en hemiabdomen derecho. A la exploración el abdomen es blando y depresible, ligeramente doloroso y con peritonismo moderado. El líquido peritoneal (LP) es turbio por lo que se instaura protocolo de peritonitis que implica administración intraperitoneal (IP) de vancomicina $2 \mathrm{gr}$. cada 4 días y ceftazidima $2 \mathrm{gr}$ cada $24 \mathrm{~h}$ hasta tener resultado del antibiograma. También se cursa recuento celular y cultivo de líquido peritoneal que confirma dos días más tarde por Microbiología que esta creciendo un gram positivo (S. Epidermidis) pendiente de tipificación final y corynebacterias por posible contaminación. Se mantiene vancomicina hasta completar 5 dosis y se retira ceftazidima. Además se detecta en frotis nasal la aparición de Staphilococus Aureus por lo que se administra Bactroban intranasal ${ }^{\circledR}$ una aplicación en cada fosa nasal dos veces al día, los primeros cinco días de cada mes. A los dos días de iniciado el tratamiento el LP es transparente

\section{Segundo episodio de peritonitis:}

El día 5/11/2011 (un mes después de primer episodio), el paciente acudió al hospital por LP turbio sin clínica asociada; se instaura de nuevo protocolo de peritonitis y se confirma S. Epidermidis. En los niveles de vancomicina en sangre del día 8/11/2011 da 9,2 mg./L (rango entre 5.0 y 10.0). Se mantiene vancomicina IP hasta completar 4 dosis. EI LP se hace transparente desde el día 09/11/2011 (a los 4 días).

\section{Tercer episodio de peritonitis:}

El día 25/11/2011 nuevo episodio de líquido turbio con escaso dolor abdominal. Se instaura de nuevo tratamiento con vancomicina + ceftazidima y se añade al tratamiento fluconazol vía oral una cápsula al día de $100 \mathrm{Mg}$.

A la espera del resultado del cultivo se plantea la posibilidad de retirar catéter según se evidencie presencia de nuevo germen o peritonitis recidivante. A los tres días de inicio del tratamiento el LP ya es transparente.

El día 2/12/2012 se confirma la presencia de S. Epidermidis, lo que sugiere peritonitis recidivante con presencia de biofilm. Se cambian antibióticos y se instaura tratamiento con ciprofloxacino $500 \mathrm{Mg}$. cada $12 \mathrm{~h}$ vía oral (durante 3 semanas) + rifampicina $600 \mathrm{Mg}$. oral (durante 12 días) y se mantiene fluconazol.

\section{Cuarto episodio de peritonitis:}

El día 14/02/2012 el paciente acude al hospital por líquido turbio. Se instaura protocolo de peritonitis con vancomicina y ceftazidima según protocolo descrito anteriormente. El día 17/02 se confirma S. Epidermidis con CMI (concentración mínima inhibitoria) a vancomicina de 4 que según la literatura se considera sensibilidad intermedia ${ }^{(5-6)}$. Por otra parte se asocia gentamicina al tratamiento según antibiograma ATB y se programa retirada de catéter de DP.

\section{Método}

Para evitar la retirada del catéter y dadas las características del paciente (joven, adaptado totalmente a la técnica y con buena diuresis residual) y consultada la bibliografía existente se identifican experiencias en las que se ha conseguido la eliminación de S. Epidermidis en peritonitis recidivantes con sospecha de biofilm utilizando daptomicina que tiene un CMI mejor que la vancomicina.

La ruta de administración de la misma es discutida por los autores que la utilizan tanto IP como IV ${ }^{(7)}$.

La administración de daptomicina IP, implica una dosis de choque de $200 \mathrm{Mg}$. (en dos litros de solución de DP), seguida de $40 \mathrm{Mg}$. en cada recambio del líquido intraperitoneal (cuatro veces al día) durante 10 días y posterior sellado del catéter más el prolongador con 350 $\mathrm{Mg}$. de daptomicina en $7 \mathrm{ml}$. durante $12 \mathrm{~h}$ una vez a la semana durante cuatro semanas ${ }^{(8)}$.

Nosotros hemos empleado la vía intravenosa (para reducir las manipulaciones) como tratamiento para la peritonitis a dosis de $6 \mathrm{mg} . / \mathrm{Kg} . / 48 \mathrm{~h}$ (dosis aceptada entre 4-6 mg./Kg./48h) y el posterior sellado del catéter y prolongador para erradicar el biofilm.

\section{Pauta de utilización de daptomicina empleada por no-} sotros. 


\section{Tratamiento de la peritonitis:}

Daptomicina $6 \mathrm{Mg} . / \mathrm{Kg} . / 48 \mathrm{~h}$ IV diluido en $50 \mathrm{ml}$. de suero fisiológico a prefundir en 30 minutos. En un total de 7 dosis (durante 15 días).

Coincidiendo con la $2^{\mathrm{a}}$ y $5^{\circ}$ dosis se controlaron los niveles de CPK en sangre por la posible destrucción de músculo que es una de las contraindicaciones del uso de la daptomicina. Siendo el resultado de los mismos aceptables y permitiendo continuar con la administración de la misma.

\section{Sellado del catéter y prolongador con daptomicina.}

El sellado se realizó en nuestra Unidad de DP por el enfermero responsable y con ayuda de una auxiliar de clínica. Se hizo un sellado semanal con $350 \mathrm{Mg}$. de daptomicina diluido en $7 \mathrm{ml}$ de suero fisiológico en un total de 4 semanas. El volumen a infundir se decidió midiendo el volumen de cebado del catéter y el prolongador.

La mecánica de actuación fue la siguiente: Previo al seIlado, se vaciaba el abdomen del paciente totalmente y se dejaba vacío durante $24 \mathrm{~h}$ (los controles bioquímicos y la función renal residual del paciente nos lo permitían).

Posteriormente se procedía a realizar un lavado con suero fisiológico del catéter más el prolongador para retirar restos de líquido peritoneal y a continuación, se ponía el sellado propiamente dicho durante $24 \mathrm{~h}$ y el paciente volvía a su domicilio.

Al día siguiente el paciente realizaba una primera infusión y luego continuaba con su tratamiento habitual de DPCA hasta la semana siguiente.

A diferencia de los sellados de de los catéteres tunelizados utilizados en HD que se preparan en la Unidad de Farmacología de nuestro hospital, los sellados utilizados para el catéter de diálisis peritoneal, se preparan, ma- nipulan y administran en nuestra Unidad siguiendo las mismas medidas que se implementan para el cambio de prolongador (Ver figura 1).

\section{Resultados}

En la actualidad y 6 semanas después del último sellado, el paciente se encuentra asintomático y sin haber presentado ningún síntoma de posibles recidivas por lo que consideramos el episodio cerrado y el cuadro clínico curado.

Hay que decir que el primer drenaje posterior al primer sellado, el liquido peritoneal apareció turbio (con gran alarma por parte del paciente) y que se justificaba por la reacción con el liquido peritoneal nuevo recién infundido. En los siguientes cambios de bolsa se normalizó el aspecto del LP, aunque no se realizó ningún recuento celular.

En los siguientes sellados y como medida de seguridad y control, se tomaron muestras tanto del LP previo al sellado como del LP del primer drenaje posterior al seIlado para hacer un recuento celular de los tres últimos sellados.

El resultado obtenido nos dio un recuento que estaba dentro de los parámetros normales e decir menos de 100 leucocitos por campo.

\section{Discusión}

Basado en nuestra experiencia y en la bibliografía publicada, ante episodios de peritonitis recurrentes con sospecha de colonización del germen y formación de biofilm, el sellado con antibiótico del catéter y prolongador han demostrado su eficacia terapéutica en la erradicación del episodio de peritonitis, evitando así la re-

\begin{tabular}{|l|l|l|}
\hline & DAPTOMICINA INTRAVENOSA & DAPTOMICINA EN SELLADO \\
\hline Dosis & $6 \mathrm{Mg} . / \mathrm{kg} . / 48 \mathrm{~h}$ & $350 \mathrm{mg} . / \mathrm{semana}$ \\
\hline Vía de administración & Intravenosa & Sellado de catéter + prolongador \\
\hline Dilución & $50 \mathrm{ml}$. de suero fisiológico 0,9\% & $7 \mathrm{ml}$. de suero fisiológico 0,9\% \\
\hline Tiempo de perfusión & 30 minutos & Bolo \\
\hline Dosis Total & 7 dosis $(15$ días) & 4 semanas \\
\hline Observaciones & Controles de CPK en la $2^{\text {a }}$ y $5^{\text {a }}$ dosis & Vaciado peritoneal 24h. Recuento celular pre y post sellado \\
\hline
\end{tabular}

Figura 1. Pauta de peritonitis recidivante con sospecha de biofilm 
tirada del catéter y la salida del paciente de la técnica. Por otra parte y aunque nosotros hemos utilizado la daptomicina por vía intravenosa y en el sellado con el abdomen vacío, somos conscientes en línea con lo manifestado por otros autores que queda por determinar la estabilidad fisicoquímica real de la daptomicina en los fluidos de DP.

Recibido: 15 Enero 1013

Revisado: 25 Enero 2013

Modificado: 8 Febrero 2013

Aceptado: 10 Febrero 2013

\section{Bibliografía}

1. Woodrow G, Turney JH, Brownjohn AM. Technique failure in peritoneal dialysis and its impact on patient survival. Perit Dial Int 1997;17:360.

2. Holley HL, Piraino BM. Complications of peritoneal dialysis: diagnosis and management. Semin Dial 1990;3:245.

3. Li PK, Szeto CC, Piraino B, Bernardini J, Figueiredo $A E$, Gupta $A$, et al. Peritoneal Ddialysis-related infections recommendations: 2010 Update.Perit Dial Int 2010; 30:393-423.

4. Raad I, Hanna $H$, Jiang $Y$, Dvorak $T$, Reitzel $R$, Chaiba $G$, et al. Comparative activies of daptomycin, linezolid and tigecycline against catheter-related methicilin resistant Sthaphycoccus bacteriemic isolates embedded in biofilm. Antimicrob Agents Chemother 2007;51:1656-6.

5. Burklein D, Heyn J, Kirchhoff C, Ozimek A, Traunmuller $F$, Joukhadar $C$, et al. Analysis of plasma and peritoneal fluid concentrations of daptomycin in a patient. Int J Antimicrob Agents 2008;32(4):369-71.

6. Huem SC, Hall I, Topal J, Mahnenmith R, Brewster U, Abu-alfa A, Successful use of intraperitoneal daptomycin in the treatment of vancomycin-resistant enterococcus peritonitis. Am J Kidney Dis 2009, 54(3):538-41.

7. Levy F., Camarero V., Blasco A., Ortega M. P., Abrigar P. Tratamiento con daptomicina intravenosa en una recidiva de peritonitis por Staphylococcus epidermidis. Nefrología 2011;31(3):374-5.

8. García-López L., Gómez L., Fernández-Reyes M. J. Administración intraperitoneal de daptomicina. Nefrología 2011;31(3):375-6. 